\title{
Histopathological Studies on Trichodinosis of Farmed Oreochromis niloticus
}

\author{
Mohamed Arafa Adly ${ }^{1}$, Mohamed Abdelaziz Ahmed Abd El-Galil ${ }^{2}$, Fayza M. Soliman ${ }^{1}$, \\ Fatma El Zahraa A. A. Ahmed ${ }^{1}$ \\ ${ }^{1}$ Zoology Department, Faculty of Science, Sohag University, Sohag, Egypt \\ ${ }^{2}$ Fish Diseases and Management Department, Faculty of Veterinary Medicine, Sohag University, Sohag, Egypt
}

\section{Email address:}

m.adly@yahoo.com (M. A. Adly), abdelgalil1997@yahoo.com (M. A. A. Abd El-Galil), f.soliman@yahoo.com (F. M. Soliman), toda_2008@yahoo.com (F. A. A. Ahmed)

\section{To cite this article:}

Mohamed Arafa Adly, Mohamed Abdelaziz Ahmed Abd El-Galil, Fayza M. Soliman, Fatma El Zahraa A. A. Ahmed. Histopathological Studies on Trichodinosis of Farmed Oreochromis niloticus. American Journal of Life Sciences. Special Issue: New Horizons in Basic and Applied Zoological Research. Vol. 3, No. 6-1, 2015, pp. 30-37. doi: 10.11648/j.ajls.s.2015030601.15

\begin{abstract}
The present study was planned to study the trichodinosis in the farmed freshwater fish Oreochromis niloticus and investigate the histopathological alterations on the skin and gills. The diseased fish had signs of irritation in the form of erratic swimming, swimming near borders, scratching against hard objects, detached scales, excessive and turbid mucus and ulcerations; and signs of asphyxia in the form of rapid operculum movement, surfacing and piping or gasping. Histopathological examination using light microscopy on the skin of $O$. niloticus with moderate trichodinosis infection revealed detachment of the epidermis and disarrangement of the collagen bundles in dermis. Heavy infections caused sloughing of the epidermis and the remaining dermis had disarranged collagen bundles and was infiltrated with melanin- carrying cells, forming a thick dark band. Scanning electron micrographs of infected skin surface showed cracked and irregular thickness of squamous epithelium at the whole surface with erosions and marked ulcerations. Histopathological examination using light microscopy on gills of $O$. niloticus with moderate trichodinosis infection revealed erosions in the epithelial lining cells of the secondary lamellae, causing thinning of their peripheral portions. Heavy infections caused hyperplasia and an intense lamellar epithelial lifting. Scanning electron micrographs of gill arches showed the gill filaments with irregular thickness at their whole lengths. Moreover, filamentary and lamellar surfaces were cracked, spotted and had small notches due to the crawling movement of the Trichodina parasites.
\end{abstract}

Keywords: Trichodinosis, Trichodina sp., O. niloticus, Histopathology, SEM, Skin and Gills

\section{Introduction}

Like humans and other animals, fishes may suffer from diseases which lead to severe economic losses. Fish diseases now are widely spread due to high water pollution which changes the water quality that reduces the immunity of fishes to diseases [1]. The intensification of fish in the farms and/or deteriorating water quality such as unsuitable water temperature, $\mathrm{pH}$, carbon dioxide and free ammonia concentrations create the disease problem [2], also the water pollution accelerate the life cycle of the parasites and promote their spread [3]. Most of fish diseases especially in warm water fishes might be occurred as a result of parasitic infections that are caused by ectoparasitic and/or endoparasitic organisms $[1,4]$ where a great number of animal species are capable of parasitizing on fish, ranging from microscopic protozoans to grossly visible crustaceans and annelids [5]. Ectoparasites are typically present either on the surface of the fish, within the gills, or both and the ectoparasitic forms are detected in direct microscopic examination of skin and gill scrapings from alive (or freshly killed) fish [6]. Ciliates including Trichodina spp. are the most identified pathogenic protozoan ectoparasites where they can easily spread among most of fish hosts causing serious threats to fish, particularly under culture conditions [7].

Trichodina parasites are circular in shape; side view of the organism reveals a saucer or dome shape that glides rapidly over the gill and skin surfaces [8]. These organisms are 50 microns in diameter, with rows of cilia at both ends and the rest of the body is non-ciliated [9]. Trichodina is a global parasite exists throughout the year [10]. It can parasitize on all fish species and can disperse via translocation of their cultured 
fish hosts [6]. It was recorded in Egypt on Oreochromis niloticus, Clarias gariepinus, Tillapia zilli and Ctenopharyngodon idella [1, 3, and 11]. Tilapia are considered as the most popular fish in Egypt, several species of tilapia are cultured commercially, but Nile tilapia Oreochromis niloticus is the predominant cultured species in Egypt and worldwide. The species is favored among aquaculturists due to its ability to tolerate a wide range of environmental conditions, fast growth, successful reproductive strategies, and ability to feed at different trophic levels [12].

Trichodinosis (slime disease or trichodiniasis) is one of the protozoan diseases caused by ectoparasitic ciliates called Trichodina spp. It is frequent in freshwater and marine fishes that are stressed by harsh winter conditions, overcrowding and high water pollution. Trichodinosis can be diagnosed based on the identification of the protozoan parasites on the skin scrapings and gill arches [13]. In the case of light infection when a few number of Trichodina parasites are present on fins skin and gills, they act as ectocommensals and the infected tissues remain in a good health condition. The clinical signs and histopathological changes of trichodinosis were detected only when high number of Trichodina is present then they considered a pathogenic ciliates and cause severe injury [2]. This disease is regarded as a main cause of fish mortality in freshwater farms [14] and it manifests in the form of restlessness, loss of appetite, loss of condition, signs of irritation including swimming near borders and scratching against hard objects. Excessive mucous secretions were observed in some fishes, and respiratory function can be impaired in gill infections [6]. Most trichodinids feed on the disrupted cells of the host gills and skin and may even penetrate deeply into the tissues causing severe injuries [13]. Histology and Histopathology have a central role in disease diagnosis by microscopic examination of thin, stained tissue sections to determine changes in tissues due to pathogens.

In general, fish organs differ from the other exposed vertebrate organs because of its watery environment. For example the living epidermal cells of fish skin are in direct contact with the environment and subjected to at least two types of stresses, osmotic pressure gradients between the cells and the water and physical forces originating from the water itself, the other environmental hazards as rocks and from the harming organisms such as fungi, bacteria, and water-born parasites to the skin [15]. The skin of fish mainly consists of two layers of different composition; the epidermis (the upper part) and the cutis (the lower part). Some aspects of the ultrastructure of the skin of several fishes have been studied before; epidermis [16], dermis [17] and chromatophores [18]. Regarding the gills of bony fishes they are consisting of main trunk called gill arch which bears two rows of filaments called primary lamellae that are provided by many regularly arranged secondary gill lamellae originate perpendicular on their axis [19]. Concerning the pathogenic effects of trichodinosis on skin, several investigators showed that the trichodinosis causes mainly excessive mucus production, hyperplasia, necrosis and edema [20]. Also epithelial cells lined both primary and secondary gill lamellae are usually subjected to severe attack by Trichodina parasites and this induces excess mucus production and cellular growth leading to hypertrophy and secondary hyperplasia, sometimes necrosis or complete destruction of gill epithelium [2].

Because of the presence of Trichodina in all corners of the globe, and the existence of such protozoan ciliate in a pathogenic forms due to its high density which lead to serious disease and high economic loses, and because of the great economic importance of $O$. niloticus, this work was carried out to study the histopathological alterations of trichodinosis on the skin and gills of such fish species at Sohag Governorate.

\section{Materials and Methods}

A total number of 180 farmed $O$. niloticus were collected alive from El-Ahaywa fish hatchery at Sohag Governorate and transported to the fish laboratory of Zoology Dept., Faculty of Science, Sohag University in plastic containers partially filled with its local water and aerated by battery aerator [21]. Each season 45 fish were investigated during the period from 21-12-2011 to 20-12-2012 and the diseased O. niloticus were processed to histopathological examination.

\subsection{Clinical Investigation}

Clinical examination was carried out on alive fish. The external body surface (skin, fins, gills, eyes and other external features) were examined for the presence of any clinical abnormalities according to the method described by Noga [22]. Clinical signs and abnormalities appeared on the body surface of diseased fish were reported and photographed using HP digital camera 8 mega pixel.

\subsection{Parasitological Investigation}

Scraps from skin were prepared by curettage of the body surface and the smears were spread on a dry clean slides with a drop of water and examined under (40X) lens. Wet smears of gills were prepared by cutting the gills in petri dish then the filaments were examined under dissecting microscope. High density of trichodinids per microscopic field indicates the infection with trichodinosis [23].

\subsection{Histopathological Examinations}

\subsubsection{Light Microscopy}

After clinical and parasitological examinations, skin and gills were processed for the histological and histopathological study according to Hibiya [24]. Tissue samples were fixed in formalin $10 \%$ for $48 \mathrm{hrs}$. and were gradually dehydrated in a series of ascending concentrations of ethyl alcohol, cleared in methyl benzoate for $8 \mathrm{hrs}$. three times and then followed by three changes of toluene 2 hrs. per each. Next, the samples were impregnated and embedded in molten paraffin wax and cooled to harden. Paraffin blocks were then cut into thin sections (5-7 $\mu \mathrm{m}$ in thickness), mounted onto glass microscope slides, de-waxed and stained with Haematoxylin 
and Eosin (H\&E). All photographs were taken at the Faculty of Veterinary medicine under (Labomed) microscope at 100X magnification using progress capture program (pro 2.5) by (Ivu 3000) camera; Jenopik, Germany.

\subsubsection{Scanning Electron Microscopy (SEM)}

Samples of skin and gills were dissected, washed and fixed in $2.5 \%$ glutaraldehyde in $0.1 \mathrm{M}$ phosphate buffer $(\mathrm{pH} 7.4)$ for one week in the refrigerator. Then the samples were washed in the phosphate buffer, dehydrated in ethanol and stored in anhydrous acetone. They were subjected to critical point drying using $\mathrm{CO}_{2}$. The dried tissues were mounted, coated with gold in sputter coater and studied under Phillips-500 Scanning Electron Microscope [25].

\section{Results and Discussion}

\subsection{Clinical Signs}

In the case of light infection when few numbers of Trichodina are present on fins, skin and gills, they act as ectocommensal protozoans and the infested tissues remain in a good health condition however most of clinical signs were noticed in fish with moderate and severe infections [2, 3]. The recorded clinical signs were noticed only in moderate and severe infections and the severity of clinical signs were in correlation with the intensity of trichodinids. The clinical signs of trichodinosis in $O$. niloticus were summarized in signs of skin irritation and respiratory distress. The recorded signs of asphyxia were rapid operculum movement, surfacing and piping or gasping. The signs of irritation were noticed in the form of erratic swimming, swimming near borders, scratching against hard objects, detached scales, ulcerations on the skin and formation of excessive and turbid mucus on both skin and gills in addition to dullness and fin rot (Fig. 1). Signs of irritation might be attributed to the mechanical action of the cilia of Trichodina and crawling movement of the parasite on the surface epithelium of the skin and gills [26]. Signs of asphyxia may be attributed to the feeding behavior of Trichodina on the disrupted cells and host's gills leading to loss of gill epithelium that, consequently, causes respiratory function disorders and leads to penetration of the parasite deeply into the gill tissues [13]. The massive production of mucus is considered as a defense mechanism to eliminate the parasite or dilute its irritating effects [2]. These findings agreed with those found by Soliman et al. [11] who studied the clinical signs of trichodinosis in the same fish species.

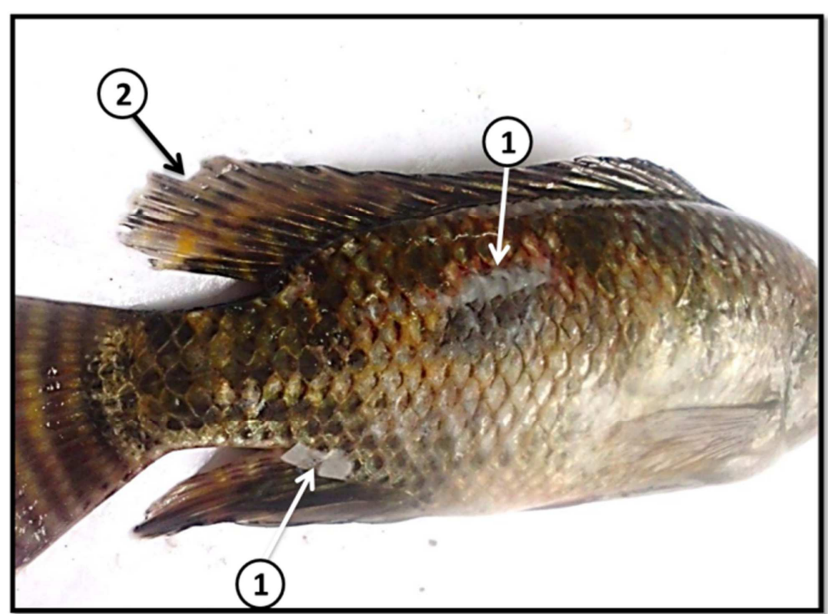

Figure 1. Photograph of diseased O. niloticus fish showing dullness appearance with detachment of scales (1) and fin rot (2).

\subsection{Parasitological Examination}

In wet mount preparations, the parasites appeared as circular or bell-shaped ciliated organisms which were highly crowding and rapidly motile (Fig. 2 a). Under higher magnification $(40 \mathrm{X})$, the parasite was shown to have several circular rows of cilia and a circle of more centrally lying hooklets (Fig. 2 b). The harmful effects of the parasite resulted from the adhesive disc of Trichodina and the sharp rim of the border membrane which bite into the surface of the host epithelial cells, and strongly act as a sucker causing host irritation. These activities of the parasites, consequently, lead to severe loss of surface epithelium of skin giving a good chance for secondary pathogens as bacteria or fungi to invade the fish $[26,27]$.

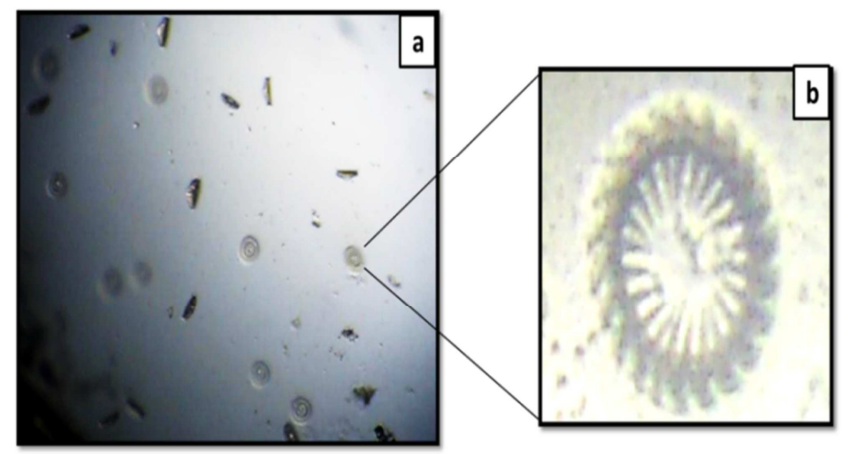

Figure 2. Photograph of wet mount slide shows the Trichodina parasites from a skin scrap; (a) (100X) and (b) (400X).

\subsection{Histological and Histopathological Studies}

\subsubsection{In Skin}

\section{(a). Light Microscopy}

Histopathological examination showed that, in contrast to the normal intact skin of $O$. niloticus which is composed of epidermis (E) that consists of stratified squamous epithelium with mucous cells in between secreting a slimy substance that covers the whole surface of the skin with a protective layer against infections [16] and cutis or dermis (D) filled with 
collagen bundles (CB) and subcutaneous skeletal muscles (SM) (Fig. 3a and b), the skin of $O$. niloticus with moderate infection had disorganized and detached epidermis with vacuolations between cells. The dermis had disarranged collagen bundles (CB) and was infiltrated with melanin carrying cells which aggregated between the skeletal muscles and the collagen fibers (Fig. 3c and d). These findings agreed with the results of Hassan [2] who previously reported these lesions on $O$. niloticus and $O$. aureus infected with trichodinosis and collected from various fish farms of Saudi Arabia and Huh et al. [28] who reported these lesions on the infected largemouth bass Micropterus salmoids from North Carolina, USA.

In severe infection, the epidermis was completely eroded and sloughed (complete loss). The remaining dermis had disarranged collagen bundles and was infiltrated with melanin - carrying cells which aggregated between the muscle layer and the collagen fibers forming a thick dark band (Fig. 3 e and f). The latter finding may explain why the heavily infected fish had the characteristic of dark coloration of body [2]. In addition to the previous observed lesions, Huh et al. [28] reported severe epithelial hyperplasia in the epidermis of the infected largemouth bass Micropterus salmoids from North Carolina, USA that wasn't observed during this study. Also, Hassan [2] reported that the dermis was edematous and infiltrated with leucocytes associated with the melanin-carrying cells which were observed alone in this study aggregated between collagen fibers and skeletal muscles.

\section{(b). Scanning Electron Microscopy (SEM)}

Scanning electron micrographs showed that, in contrast to the intact skin surface of $O$. niloticus that is composed of intact layer of squamous epithelium (Figure $4 \mathrm{a}, \mathrm{c}$ and e), the infected skin with trichodiniasis showed cracked and irregular thickness at the whole surface with erosions and coagulative necrosis of the surface epithelial cells (Fig. 4 b, d and f). Some of these lesions were observed previously by Gostin et al. [29] who used the (SEM) in the examination of the skin micromorphology and modifications induced by bacterial infections on the epidermis of common carp (Cyprinus carpio) and brown trout (Salmo trutta fario) at Romania.
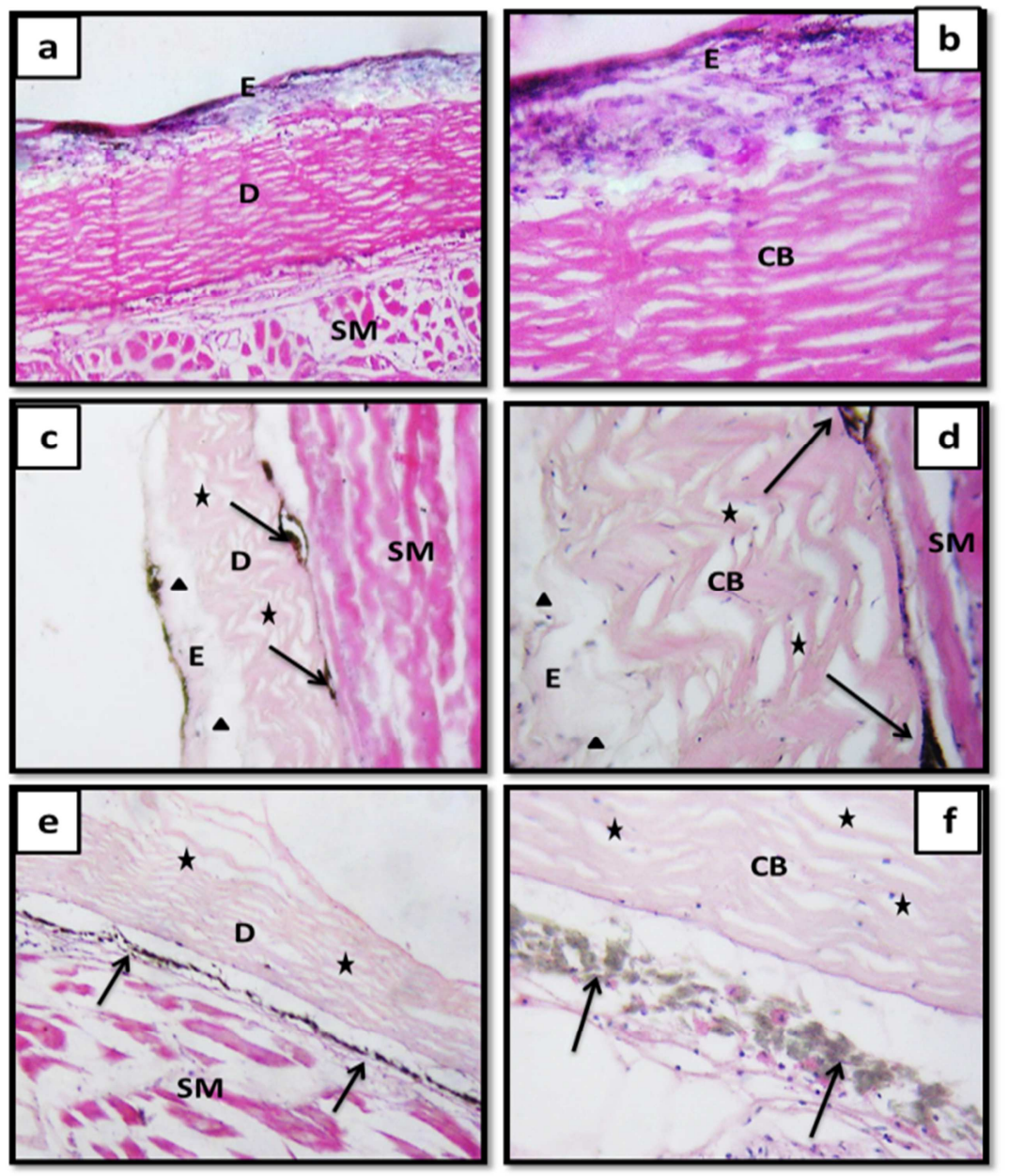

Figure 3. Vertical sections of O. niloticus skin; ( $a$, c and e) Photomicrographs at magnification (100X) and (b, d and f) at magnification (400X) (H \& E). (a and b) represent control group, showing (E) Epidermis, (D) Dermis filled with collagen bundles (CB), and (SM) Skeletal muscles. (c and d) represent moderate infection revealed detachment and vaculations within the epidermis (triangles); (e and f) represent severe infection revealed sloughing of the epidermis in addition to disarranged collagen bundles in dermis (stars) and aggregation of melanin-carrying cells between the dermis and skeletal muscles (arrows) in both cases. 

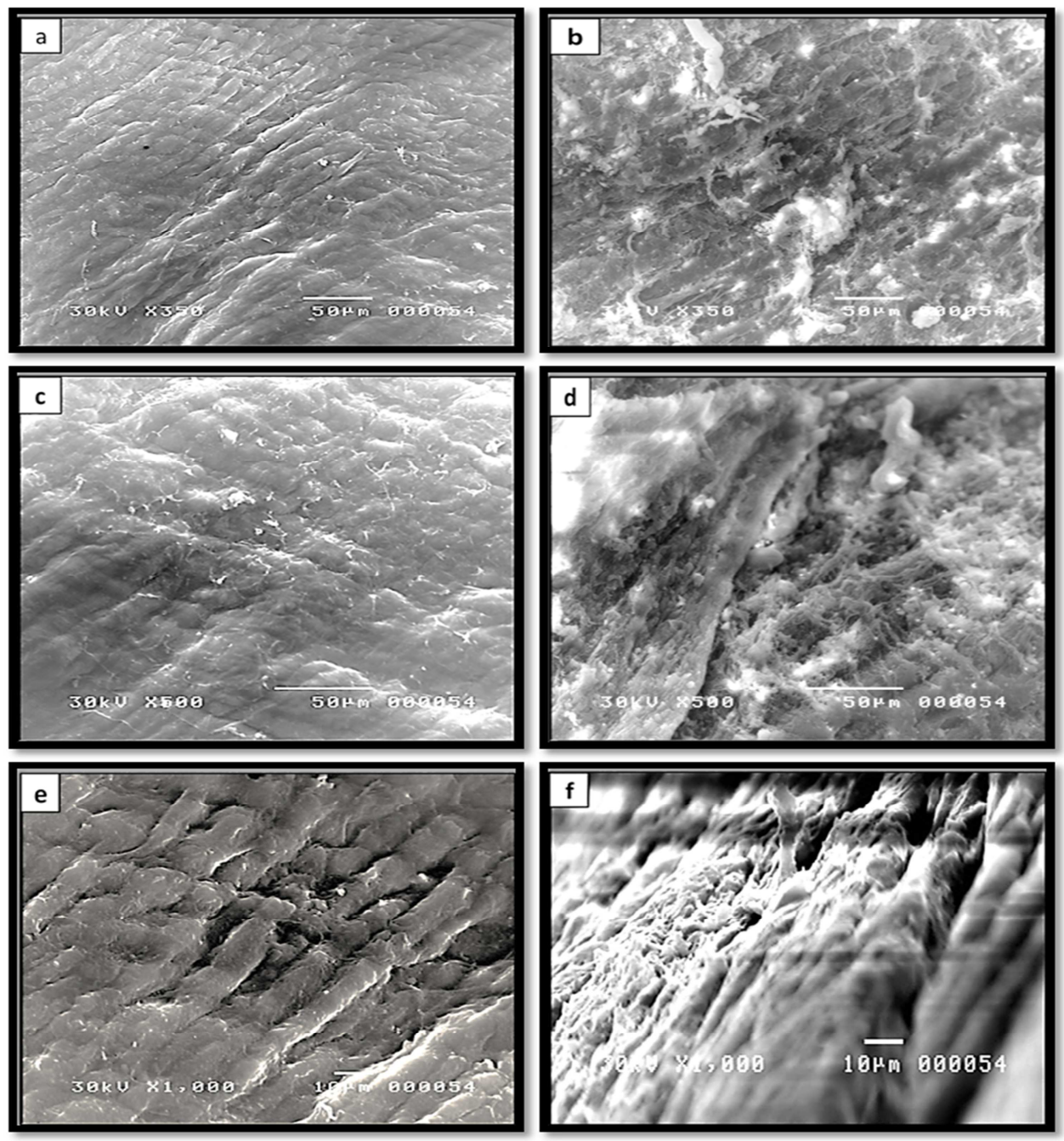

Figure 4. Scanning electron micrographs at different magnifications (350X, 500X and 1000X) of the skin surface of O. niloticus; (a, c and e) represent control group showing intact skin surface which was clear with regular squamous epithelium. (b, $d$ and f) represent the infected group showing cracked and irregular thickness of squamous epithelium at the whole surface with marked ulceration of the skin indicating the presence of skin erosions.

\subsubsection{Gills}

\section{(a). Light Microscopy}

The normal intact gill arch of $O$. niloticus bears two rows of gill filaments called Primary lamellae (Pl) which had numerous secondary lamellae (Sl) originate perpendicular on their axis; the primary lamellae are lined between the secondary lamellae by a thick stratified epithelium (E) composed of chloride (c) and mucous ( $\mathrm{m}$ ) cells; and the secondary lamellae are lined by simple squamous epithelium below that epithelium there are lamellar blood sinuses separated by pillar cells (p) (Fig. 5). In contrast, the histopathological examination of the infected gill arches by trichodiniasis revealed proliferative changes in the epithelial lining cells of both primary and secondary gill filaments. In moderate infection, the epithelial lining cells of some secondary lamellae were detached causing epithelial lifting (epithelium detachment) and this resulted in interstitial edema; the secondary lamellae showed erosions, thinning and shortening of their peripheral portions. Some secondary lamellae showed hyperplasia at their bases or tips or both causing partial fusion of the adjacent lamellae (Fig. 6). Hassan [2] reported the same lesions on farmed $O$. niloticus and $O$. aureus infected with trichodinosis at Saudi Arabia.
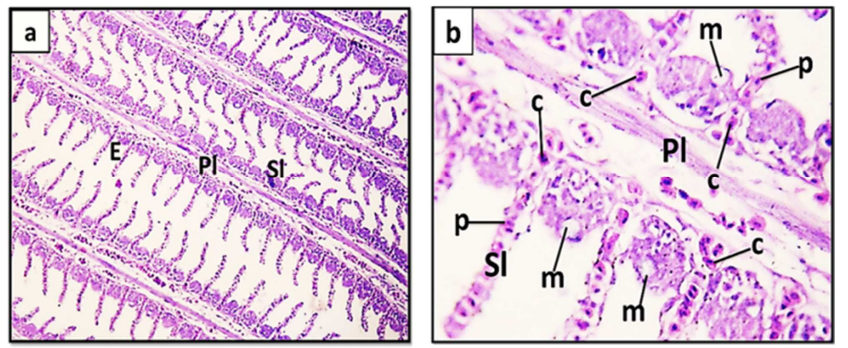

Figure 5. Sagittal section of a gill arch of non-infected $O$. niloticus showing intact gill filaments; (a) Photomicrograph at magnification $100 X$ and (b) at magnification $400 X$ ( $H \& E$ ). (Pl) Primary lamellae, (Sl) Secondary lamellae and (E) stratified epithelium, (m) mucus cell, (c) chloride cell and (p) pillar cell. 

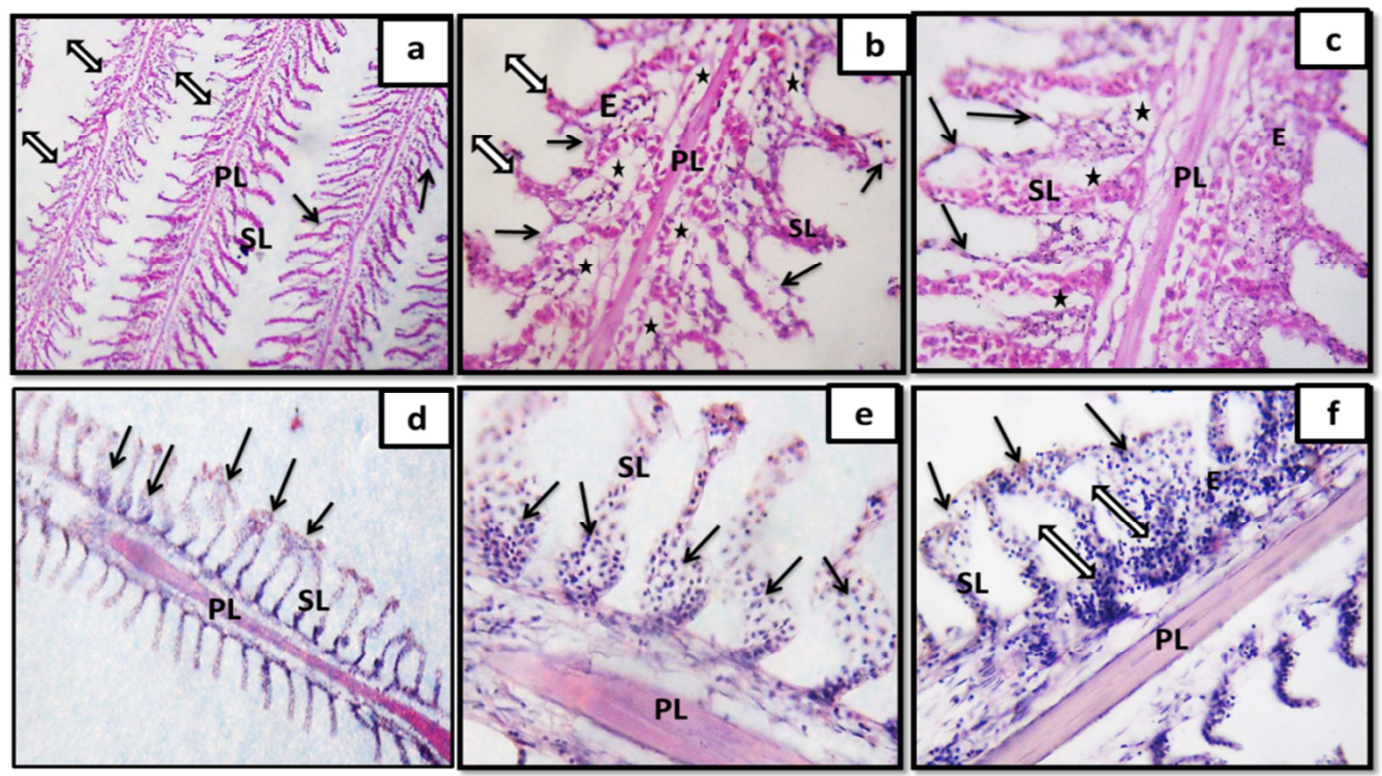

Figure 6. Sagittal sections of gill arches of $O$. niloticus had signs of moderate infection with trichodinosis; (a and d) photomicrographs at magnification (100X) and $(b, c, e$ and f) at magnification $(400 X)(H \& E) .(b, c)$ showing epithelial detaching in some secondary lamellae (arrows) and interstitial edema (stars), also (b) showed epithelial erosions causing thinning and shortening of the secondary lamellae of one primary lamella (double head arrows). (d, e and f) showed hyperplasia at both tips and bases of some secondary lamellae of one primary lamella leading to fusion of adjacent lamellae (arrows) and inflammatory cells at the bases of some secondary lamellae (double head arrows).

In severe infections, there was an irregularity of the secondary lamellae in the form of thinning and shorting of some of them, an intense lamellar epithelial lifting (epithelium detachment) and severe hyperplasia in some others. Severe hyperplasia was in the form of extensive epithelial proliferation leading to shorting of some secondary lamellae and fusion of adjacent secondary lamellae so, one, two or three lamellae appeared adherent to each other (Fig. 7). Therefore, fish which were heavily infected by Trichodina $s p$. exhibited a distinct signs of respiratory dysfunction. Similar lesions were previously reported by Hassan [2] on the farmed $O$. niloticus and $O$. aureus infected with trichodinosis at Saudi Arabia; also Yemmen et al. [10] reported these lesions on the infected gills of Solea aegyptiaca in Tunisia.
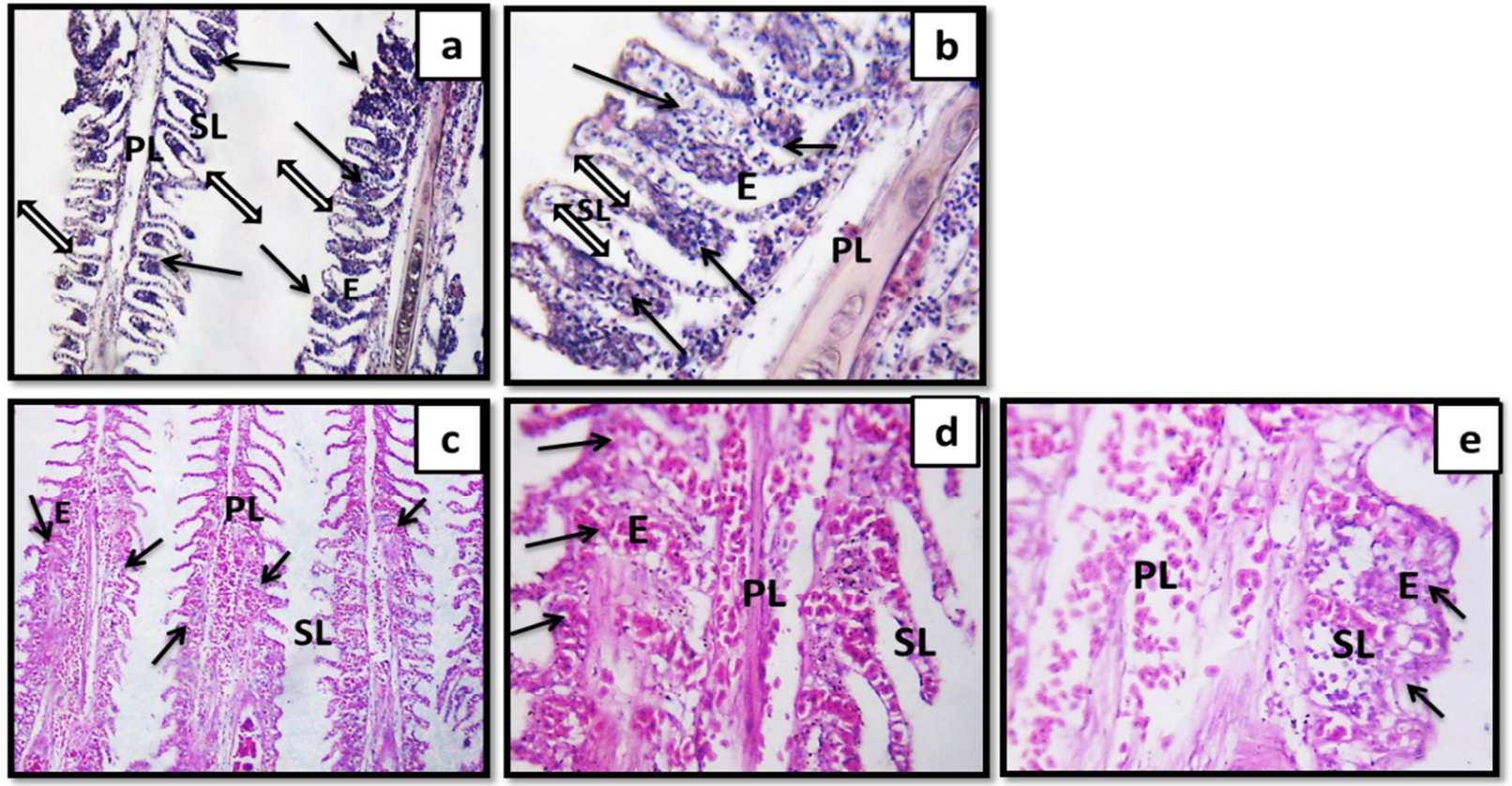

Figure 7. Sagittal sections of gill arches of $O$. niloticus had signs of severe infection with trichodinosis; (a and c) photomicrographs at magnification (100X) and $(b, d$ and e) at magnification $(400 X)(H \& E)$. In photo (a), the arrows refer to at hyperplasia and the double head arrows refer to at intense lamellar epithelial lifting in both primary and secondary lamellae. In photo (b), the arrows refer to at inflammatory cells between secondary lamellae. Photos (c and d) showed severe hyperplasia in some primary lamellae (arrows) causing shortening of adjacent secondary lamellae. Photo (e) showed severe hyperplasia in a primary lamella causing complete fusion of some adjacent secondary lamellae so one, two and three lamellae appeared as one. 


\section{(b). Scanning Electron Microscopy (SEM)}

Scanning electron micrographs showed that, in contrast to the intact surface of the gill arch of $O$. niloticus which bears several small filament trunks called primary lamellae that are provided by many regularly arranged secondary lamellae (Fig. $8 \mathrm{a}, \mathrm{c}, \mathrm{e})$, the infected gill filaments appeared cracked with irregular thickness at their whole lengths due to erosions. Secondary gill lamellae were greatly thickened curved and appeared shorter (Fig. 8b, d). The lamellar surface was spotted with several small notches (n) which may be attributed to the crawling movement of the Trichodina on their surfaces. Moreover, some of secondary lamellae were fused to each other and appeared as one thick lamella because of severe hyperplasia (Fig. 8d, f). Same lesions were observed by Hassanain et al. [25] when studding the effect of lead acetate exposure on fingerlings of Nile Tilapia $O$. niloticus.
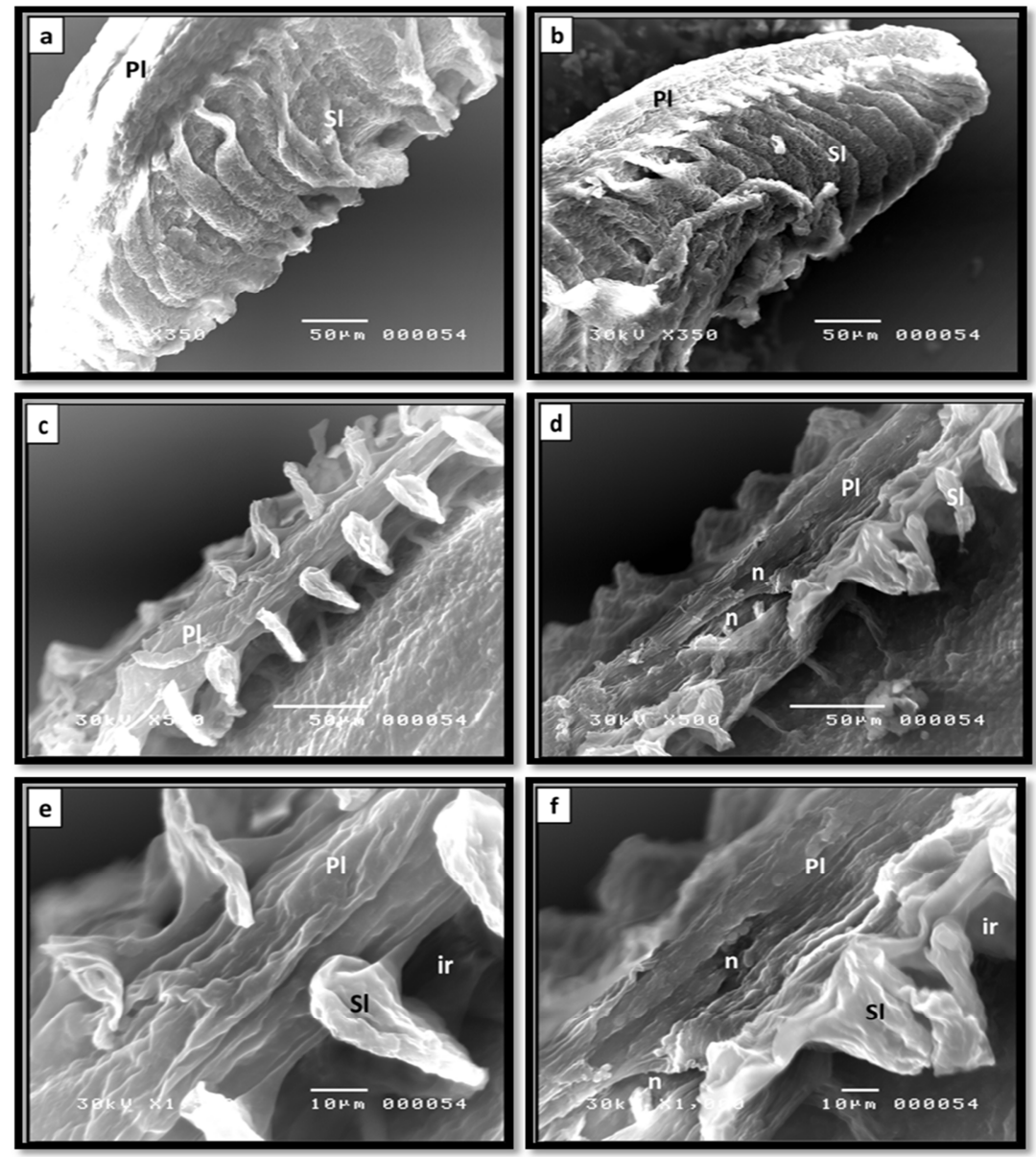

Figure 8. Scanning electron micrographs of O. niloticus gills; (a, c and e) represent control group at different magnifications (350X, 500X and 1000X), showing intact gills surfaces, primary lamellae (Pl), secondary lamellae (Sl) and the inter-lamellar region (ir) which was clear. (b, $d$ and f) represent the infected group at the same magnifications, showing the gill filaments with cracked surfaces and irregular thickness at their whole length. Moreover, small notches (n) appeared clearly on the surfaces and two secondary lamellae appeared adhere to each other.

\section{Conclusion}

On the light of above mentioned results it could be concluded that the trichodinosis affects freshwater fishes causing serious damage for the diseased fish. The severity of infection was light, moderate and severe according to the density of Trichodina parasites per microscopic field. Histopathological investigation, using light and electron microscopy, of the skin and gills of $O$. niloticus was carried out only in the case of moderate and severe infections and revealed proliferative changes in the epithelial lining cells causing several clinical signs on infected fish including irritation and respiratory distress.

\section{References}

[1] El-Seify, M. A.; Zaki, Mona S.; Abdel Razek, Y. D.;Hossam, H. A.; Osman, K. A. and Attia, A. A. (2011b): Study on Clinopathological and Biochemical Changes in Some Freshwater Fishes infected With External Parasites and Subjected to Heavy Metals Pollution in Egypt. J. Lif. Sci., 8 (3): 401-405.

[2] Hassan, M. A. H. (1999): Trichodiniasis in Farmed Freshwater Tilapia in Eastern Saudi Arabia. J. KAU: Mar Sci., 10: 157-168. 
[3] El-Seify, M. A.; Zaki, Mona S.; Abdel Razek, Y. D.; Hossam, H A.; Osman, K. A. and Attia, A. A. (2011a): Seasonal Variations and Prevalence of Some External Parasites Affecting Freshwater Fishes Reared at Upper Egypt. J. Lif. Sci., 8 (3): 397-400.

[4] Hussain, S.; Hassan, M. Z.; Mukhtar, Y. and Saddiqui, B. N. (2003): Impact of environmental pollution in human behaviour and up-left of awareness level through mass media among the people of Faisalabad city. Int. J. Agric. Biol., 5: 660-661.

[5] Eissa, I. A. M (2002): Parasitic fish diseases in Egypt, 1st. edition, pp: 52-53. Dar El-Nahdda El- Arabia publishing.

[6] Abowei, J. F. N.; Briyai, O. F. and Bassey, S. E. (2011): A Review of Some Basic Parasite Diseases in Culture Fisheries Flagellids, Dinoflagellids and Ichthyophthriasis, Ichthyobodiasis, Coccidiosis, Trichodiniasis, Heminthiasis, Hirudinea Infestation, Crustacean Parsite and Ciliates. Brit. $J$. of Pharmacol. \& Toxicol., 2 (5): 213-226.

[7] Jia-yun, Y.; Xi-lian, L.; Jin-yu, S.; Xiao-yi, P.; Gui-jie, H.; Yang Xu; Wen-lin, Y.; Hongshun, R.; Xiao-lin, L. (2011): Isolation of bioactive components from Chelidonium majus $L$. with activity against Trichodina sp.. J. Aquacul., 318: 235-238.

[8] Robert, M. D. (2003): protozoan parasites. Southern Regional Aquaculture Center (SRAC) publication no. 4701.

[9] Robert, B. M. Jr. (2013): External Protozoan Diseases of Fish. $\mathrm{http}: / / \mathrm{www}$. com/articles/diseases_ext_protozoan.php.

[10] Yemmen, C.; Quilichini, Y.; HédiKtari, M.; Marchand, B. and Bahri1, S. (2010/11): Morphological, ecological and histopathological studies of Trichodina gobii Raabe, 1959 (Ciliophora: Peritrichida) infecting the gills of Soleaaegyptiaca. J. Protistol., 6 (4): 258-263.

[11] Soliman Fayza, M.; Abd El-Galil, M. A. A.; Adly, M. A. and Ahmed Fatma El Zahraa, A. A. (2013): Studies on Trichodinosis of Some Cultured Freshwater Fishes at Sohag Governorate. J. life Sci., 10 (4): 1400-1409.

[12] Grammer, G. L.; Slack, W. T.; Peterson, M. S.; and Dugo, M. A. (2012): Nile Tilapia Oreochromis niloticus (Linnaeus, 1758) establishment in temperate Mississippi, USA: multi-year survival confirmed by otolith ages. J. compil. Aquat. Invas., 7 (3): $367-376$

[13] El-Tantawy, S. A. M and El-Sherbiny, H. A. E. (2010): Ectoparasitic trichodinians infecting catfish Clarias gariepinus inhabiting Nile Delta Water of the River Nile, Dakahlia Province, Egypt. J. of Amer. Sci., 6 (9): 656-668.

[14] Abd El-Galil, M. A. A. and Aboelhadid, S. M. (2012): Trials for control of trichodinosis and Gyrodactylosis in hatchery reared Oreochromis niloticus fries by using Garlic. Vet. Parasitol., 185: 57- 63.

[15] Hawkes, J. W. (1974): The Structure of Fish Skin, I. General Organization. Cell Tiss. Res., 149: 147- 158.

[16] Whitear, M. (1971): Cell specialization and sensory function in fish epidermis. J. Zool. (Lond.), 163: 237-264.
[17] Fishelson, L. (1972): Histology and ultrastructure of the skin of Lepadichthys lineatus (Gobiesocidae: Teleostei). Marine Biol., 17: 357-364.

[18] Fujii, R. (1969): Chromatophore and pigments. In: Fish physiology (eds. W. S. Hoar, D. J. Randall), vol. III, p. 307-353. New York: Academic Press.

[19] Figueiredo-Fernandes, A.; Ferreira-Cardoso, J. V.; Garcia-Santos, Sofia; Monteiro, Sandra, M.; Carrola, J.; Matos, $\mathrm{P}$ and Fontaínhas-Fernandes, A. (2007): Histopathological changes in liver and gill epithelium of Nile tilapia, Oreochromis niloticus, exposed to waterborne copper1 Pesq. Vet. Bras., 27 (3):103-109.

[20] Abdel-Meguid, M. (2001): Trichodiniasis as a cause of mortality among infected Tilapia zilli with special emphasis on its control using Earthtec. Egypt. J. Aquat. Biol. \& Fisk., 5 (2): 95-104.

[21] Abo-Esa, J. F. K. (2008): Study on Some Ectoparasitic Diseases of Catfish, Clarias gariepinus with their Control by Ginger, Zingiber officiale. Medit. Aquacul. J., 1 (1): 1-9.

[22] Noga, E. J. (2000): Fish Diseases. Diagnosis and Treatment. Text book, Iowa State University Press, ISBN 0-8138-2558-X.

[23] Bartholomew, J. L. (2003): Salmonid ceratomyxosis. In: Suggested Procedures for the Detection and Identification of Certain Finfish and Shellfish Pathogens. Blue Book $5^{\text {th }}$ Ed., Volume 2, Fish Health Section, American Fisheries Society.

[24] Hibiya, T. (1982): An Atlas of Fish Histology. No. 1, 1-5, Kodansha Ltd., Tokyo.

[25] Hassanain, M. A.; Abbas, W. T. and Ibrahim, T. B. (2012): Skeletal ossification impairment in Nile Tilapia (Oreochromis niloticus) after exposure to lead acetate. Pakistan J. of Biol. Scis., 15 (15): 729-735.

[26] Abd El-Galil, M. A. A. (1998): Studies on some fish pathogens affecting freshwater fishes in Beni-Suef hatchery. Thesis of M. V. Sc. Fish Diseases and management. Fish Dept., Fac. Vet. Med., Beni-suef, Cairo univ.

[27] Reed, P.; Ruth F. F. and Ruth, E. K. (2003): Monogenean Parasites of Fish. This document is FA-28, one of a series from the Department of Fisheries and Aquatic Sciences, Florida Cooperative Extension Service, Institute of Food and Agricultural Sciences, University of Florida.

[28] Huh, M. D.; Thomas, C. D.; Udomkusnsri, P. and Noga, E. J. (2005): Epidemic trichodinosis associated with sever epidermal hyperplasia in largemouth bass, Micropterus salmoides from North Carolina, USA. J. of Wildlife Dis., 41 (3): 647-653.

[29] Gostin, I. N.; Neagu, A. N. and Vulpe, V. (2011): SEM investigations regarding skin micromorphology and modification induced by bacterial infections in Cyprinus carpio and Salmo trutta fario. Inter. J. of Ener. and Environ., 2 (5): 274-281. 